\title{
AS INTERVENÇÕES DO ALUNO NO DISCURSO DE SALA DE AULA
}

\section{Maria Francisca Oliveira Santos ${ }^{(*)}$}

Resumo: Professores e alunos em ambiente de sala de aula comumente estabelecem conversação assimétrica, o que se justifica, muitas vezes, pela existência de longos turnos dos primeiros em relação aos últimos. O texto que utilizam apresenta elementos constitutivos como o tópico discursivo, o turno, os marcadores conversacionais e o par adjacente. Muita teorização existe em relação a esses fatores que encontram explicações principalmente nos estudos conversacionais da linguagem. Apesar de esses elementos terem grande importância nas relações entre professor e alunos no ambiente especificado, apenas o par adjacente desperta nossa atenção pelo fato de observarmos que quase exclusivamente a participação do professor tem sido motivo de grandes investigações teóricas. Este trabalho tem por objetivo analisar criticamente esse discurso para verificar que razões, nas relações de poder, fazem com que a participação do aluno seja demarcada pelas intervenções do professor, em um corpus provindo de aulas filmadas em turmas de 6 série do ensino fundamental, em uma escola da rede pública em Maceió-Alagoas.

Palavras-chave: Discurso, salde aula, par adjacente

Considerações preliminares

O discurso de sala de aula caracteriza-se por ser assimétrico, apesar do esforço desprendido pelos que defendem a existência de um possível caráter simétrico, surgido pelas trocas constantes de turnos entre professor e alunos. Apesar de isso acontecer, é o professor quem detém o comando das atividades nesse espaço ideológico, restando para o aluno reproduzir a fala dos outros (do autor do texto, do livrotexto e do próprio professor), não tendo produções espontâneas e autênticas provindas de seu trabalho na negociação do sentido. Essa assimetria advém das circunstâncias peculiares da relação hierárquica

(*) Universidade Federal de Aalagoas. 
que é imposta entre professor e aluno, uma vez que a autoridade assumida pelo professor no sentido de manter a ordem na sala impõe necessariamente ao aluno uma atitude passiva, o que se observa pelo tipo de participação durante as aulas, revelado por falas que indicam respostas sobre apenas o que lhe é autorizado dizer. É o professor quem detém o conhecimento julgado relevante pela sociedade. Por outro lado, o aluno tem conhecimento disso, como da sua carência cognitiva, reconhecendo na figura do professor, o ponto de onde adviria o suprimento da sua carência.

Considerando que este trabalho analisa o discurso de sala de aula em sua manifestação oral e que a conversação entre os interlocutores é assimétrica, elegemos entre o turno, o tópico discursivo e os marcadores conversacionais, o par adjacente perguntas e respostas - como foco de atenção, porquanto as respostas dos alunos às perguntas do professor limitam-se a afirmar ou negar o questionado ou a escolher dentre alternativas a mais conveniente ou ainda a prosseguir o desenvolvimento do tópico discursivo, fornecendo respostas que não lhe exigem muito esforço.

O evento comunicativo é a exposição em sala de aula, constituindo-se, segundo Fávero et aliae (1999), por uma situação discursiva de caráter formal e um evento de fala institucional, com tema prévio e bem preparado, tendo participantes de posição social diferente - professor e alunos - e canal caracterizado por ser face a face. A prática discursiva desse evento comunicativo vai envolver, em primeiro lugar, uma análise de como os participantes procedem em relação às perguntas e às respostas em sala de aula, para, depois, abranger um procedimento crítico por envolver uma concepção tridimensional em que o texto, a prática discursiva e a social são elementos constitutivos dessa prática.

As perguntas e as respostas no discurso de sala de aula

O texto conversacional apresenta, segundo Fávero et aliae (op. cit.) quatro elementos básicos que contribuem para sua organização, quais sejam: o turno, o tópico discursivo, os marcadores conversacionais e o par adjacente. Numa conversação, seja de caráter simétrico ou assimétrico, os participantes usam a palavra ou silenciam, o que vai constituir a sua entrada nesse espaço interlocutivo. Assim, a conversação vai ser caracterizada por uma 
sucessão de tomadas de fala por esses participantes (turnos), envolvendo não somente as intervenções que informam, mas também aquelas que apenas monitoram o percurso da conversação.

Esses participantes falam sobre algo que constitui o centro das suas cognições mentais, o que pode ser chamado tópico discursivo. $\mathrm{O}$ que observamos ainda é que os mesmos falantes do ato interativo utilizam elementos que auxiliam no desenvolvimento interacional, os chamados marcadores conversacionais, que podem ser nãolingüísticos (o riso, o olhar, a gesticulação, dentre outros) e verbais. Além desses elementos, o tópico discursivo, o turno e os marcadores conversacionais, encontramos na conversação o par adjacente representado por pergunta-resposta, convite-aceitação ou recusa, pedido-concordância ou recusa, saudação-saudação, que aparece por ser elemento básico da interação.

Pelo fato de a díade formada por pergunta e resposta constituir o foco do nosso trabalho, detivemo-nos na sua análise porque as intervenções analisadas dos alunos no discurso de sala de aula do ensino fundamental apontam para uma leitura mais crítica provinda de fatores que mostram claramente as razões do seu apagamento. Para isso, observamos, em primeiro lugar, o aspecto organizacional da díade, razão por que apontamos Fávero et aliae (1999) por admitirem ser a referida díade formada por estratégias que são usadas pelos falantes com a finalidade de introduzir, continuar, redirecionar e mudar o tópico. Visto dessa maneira, no par adjacente referido, a díade pergunta-resposta tem fundamental importância por exercer as ações de - introdução, continuidade, redirecionamento e mudança do tópico, como podemos observar nos exemplos ${ }^{1}$ a seguir:

Exemplo 1

L1 - como a gente viu no primeiro dia de aula ... durante toda a $6^{\text {a }}$ série a gente vai estudar o quê ? ... os ?

L2L3L4... os seres vivos ...

(p. 1 do corpus)

1 Os exemplos 1, 2, 3, 4 e 5 foram retirados do corpus da pesquisa intitulada "Os elementos não-verbais e verbais nos estudos interativos do discurso de sala de aula do ensino fundamental". 
No exemplo 1, é L1 quem inicia a conversação com a $\mathrm{P}$ introdutória: como a gente viu no primeiro dia de aula ... durante toda a $6^{a}$ série a gente vai estudar o quê ? ... os ? Coincidentemente, por causa das relações sociais de poder, é dado ao professor o direito de iniciar oficialmente a aula, cabendo ao aluno a obrigação de responder às questões formuladas. Essa pergunta introduz, pois, o tópico dessa conversação.

\section{Exemplo 2}

L1 - então a gente viu que os seres vivos apresentam características ... muitas características ... e de cada característica dessas ... define por si só o que é vida ... né ?... o que é o ser vivo ... foi isso ?

L2L3L4 ... fo:i ...

(p. 1 do corpus)

No exemplo 2, o professor faz uma pergunta aos alunos no sentido de receber deles o consentimento, o que realmente conseguira, caracterizando assim um tipo de pergunta que tem a finalidade de dar continuidade ao tópico discursivo.

As duas estratégias apresentadas evidenciam a presença do professor que entra no turno para introduzir e para continuar o tópico discursivo. Evidenciamos, segundo Fávero et aliae (1999), que o par/adjacente representado por $\mathrm{P} / \mathrm{R}$ tem a $\mathrm{P}$ como elemento de referência maior. Coincidentemente, é o professor, no corpus analisado, quem encabeça o referido par, evidenciando o caráter de domínio centrado na sua figura em sala de aula. Ratificando ainda mais o proposto, a divisão das perguntas em polares, factuais ou de conteúdo e alternativas especifica mais ainda como o professor monitora os alunos, restando-lhes assentir para instituírem-se como participantes do processo de interlocução de sala de aula.

Segundo a divisão proposta, perguntas polares são constituídas por frases interrogativas com entonação ascendente, visando especificamente a obter do interlocutor uma resposta de caráter afirmativo ou negativo. As factuais ou de conteúdo estão voltadas à obtenção de uma informação do alocutário, sendo caracterizadas por palavras específicas que introduzem interrogação, como pronomes ou advérbios, tendo a pergunta uma entonação 
descendente. As alternativas são constituídas por uma disjunção de proposições, sendo o alocutário induzido a tomar uma decisão que seja a favor ou contra o argumento apresentado, ou ainda, que refute o questionado, podendo ocasionar o surgimento de uma terceira alternativa. Os fragmentos a seguir mostram como se dá a presença desses tipos de pergunta:

Exemplo 3

L1 ... cada ser vivo é batizado com dois nomes ... por isso que a nomenclatura é binominal ... o primeiro nome representa o gênero ... o primeiro nome de cada ser vivo representa o gênero ... e o segu:ndo a espécie ... ok ? então dois nomes ... o primeiro ... o primeiro nome representa ... o quê ? ... o gênero ou a espécie ?

L2 - gênero ... (( fala bem no fundo da sala $))$

(p. 8 do corpus)

No exemplo 3, L1 (a professora) está no turno para explicar que o ser vivo é denominado por dois nomes, quais sejam: gênero $e$ espécie. Por estar ainda no turno e por monitorar as intervenções dos alunos, L1 elabora uma pergunta de caráter alternativo: então dois nomes ... o primeiro ... o primeiro nome representa ... o quê ? ... o gênero ou a espécie?, a qual não dá margens a que o aluno exponha livremente o seu pensamento, uma vez que, além de ela já ter sido explicada anteriormente, está centrada em ou exclusivo, deixando o interlocutor sem direito de escolha. Tais ações caracterizam o estilo autoritário previsto por Kramsch (1984), em oposição ao sóciointerativo, que se destaca sobretudo por permitir a fluidez de expressão do aluno, permitida porque o professor usa palavras de estímulo positivo às suas intervenções (do aluno).

Exemplo 4

L1 - ok ... intão filo dos cordatos são todos aqueles que possuem uma coluna vertebral inclusive o homem. claro ... o homem/.../ cada filo é formado por cada classe né ? o homem está incluído ... classificado na classe dos mamíferos ... (( voltando-se e caminhando em direção aos alunos, L1 pergunta )) por que será que o homem foi classificado nessa classe ? ...

\footnotetext{
L2 - porque ele mama ...

L1 - porque ele mama enquan:to ?

L3 - pequeno ...(p. 14 do corpus)
} 
No exemplo 4, novamente o professor está no turno. Pergunta à turma a razão por que o homem está classificado entre os seres humanos, reportando-se nesse caso ao conhecimento de mundo de que o aluno dispõe, quando diz: por que será que o homem foi classificado nessa classe ?(classe dos mamíferos), o que mostra que o prcfessor deseja que o aluno seja seu interlocutor no desenvolvimento do conteúdo da aula, embora a pergunta esteja situada em uma menor escala de dificuldade.

\section{Exemplo 5}

L1 - ( ) tudo que a gente viu né ? então qual foi o último assunto que a gente viu ? ... a classificação de quem ?

L2L3L4... dos seres vivos ...

L1 - dos seres vivos ... a gente viu que teve um cientista que estabeleceu como classificar os seres vivos não fo:i ?

L2L3L4... fo:i ...

(p. 18 do corpus)

No exemplo 5, encontramos, embora num circuito fechado para resposta, pergunta de conteúdo, tudo que a gente viu né ? então qual foi o último assunto que a gente viu ? ... a classificação de quem ? e pergunta polar, dos seres vivos ... a gente viu que teve um cientista que estabeleceu como classificar os seres vivos não fo: $i$ ? Isso mostra como o professor utiliza tais instrumentos para minorar a sua exposição de conteúdo em sala de aula.

As análises apresentadas mostram a prática discursiva em sala de aula do ensino fundamental em que um dos sujeitos (o professor) é o centro das vozes desse espaço ideológico, cabendo ao aluno intervir ou não segundo diretrizes que lhe forem fornecidas. Nesse sentido, o discurso de sala de aula é entendido como "uma prática não apenas de representação do mundo, mas de significação do mundo, constituindo e construindo o mundo em significado" (FAIRCLOUGH, 2001, p.91).

Para que o discurso propicie essa construção referida, é necessário não somente atentar para os modos, segundo os quais as identidades sociais se estabelecem no discurso (função identitária), mas também observar como se dão as relações entre os participantes discursivos quanto a sua caracterização, podendo ser qualificadas como representadas e negociadas (função relacional). Segundo o 
Autor (2001), a função identitária e a relacional podem ser resumidas na interpessoal de Halliday (1978), tomando-lhe de empréstimo apenas a função textual, que, entre outras alternativas, pode tomar as informações no texto como dadas ou novas e ainda como ligadas a partes que estão antes, dentro, depois e fora do texto em análise.

Entendendo o discurso voltado às funções referidas, reforçamos o fato de ele envolver a prática social, a discursiva e, principalmente, a textual. No âmbito das relações sociais, a prática daí originária pode ser de caráter econômico, político, cultural e ideológico. Tomando apenas como exemplo o caráter político, observamos que ele pode estabelecer, manter e transformar as relações de poder, bem como as identidades coletivas (grupos, classes, dentre outras categorias) em que apareçam tais relações. Assim é que se explica o monitoramento das intervenções dos alunos no discurso analisado, porquanto as perguntas formuladas são ideologicamente organizadas de forma a impedir o aparecimento de tomadas longas de turno por parte do discente.

O discurso analisado pode ser visto também como uma prática que reproduz a sociedade ou contribui para que essa sociedade se transforme. Isso pode ser explicado por Fairclough (2001, p. 92), quando diz:

[...] as identidades de professores e alunos e as relações entre elas, que estão no centro de um sistema de educação, dependem da consistência e da durabilidade de padrões de fala no interior e no exterior dessas relações para sua reprodução. Porém, elas estão abertas a transformações que podem originar-se parcialmente no discurso: na fala da sala de aula, do parquinho, da sala dos professores, do debate educacional, e assim por diante.

A análise feita no discurso de sala de aula, observando-se especialmente o par adjacente representado por perguntas e respostas entre professor e alunos, só foi possível pelo fato de entendermos em que situação social essa prática discursiva foi produzida e distribuída entre seus interlocutores para um consumo específico que se explica pela sua organicidade em forma dialogal, de modo a um permanecer mais no turno (professor) do que os outros (os alunos). Isso somente nos é explicado porque os atos de fala constituídos por perguntas 
(polares, alternativas e factuais) e por respostas apontarem para a leitura que indica serem as intervenções dos alunos monitoradas pelas perguntas feitas pelo professor, fazendo-nos entender essa prática discursiva.

Analisando o discurso pela visão apresentada que tem, por um lado, as contribuições dadas pela análise dos aspectos organizacionais da conversação e, por outro, a abordagem de discurso em uma visão tridimensional, podemos dizer que, embora haja uma tendência para mudanças nas práticas pedagógicas de sala de aula, o aluno é conduzido a responder somente o solicitado socialmente pelo professor por estar inserido nessa prática discursiva. O professor assim se conduz por ter sido orientado numa prática pedagógica que não absorve os valores sócio-interativos que podem estar presentes na prática de sala de aula.

\section{Considerações finais}

O texto conversacional apresenta elementos para a sua constituição, assim denominados: o tópico discursivo, os marcadores conversacionais, o turno e o par-adjacente. Neste trabalho, a análise e a interpretação do par-adjacente representado por perguntas e respostas nos permitiram saber que as intervenções dos alunos provindas de atos de fala interrogativos são monitorados pelo professor. Esse plano de análise nos conduz também à posição teórica que defende ser o discurso considerado como texto e prática discursiva e social. As práticas discursivas somente se efetivam dentro da esfera tridimensional referida. 
Referências

FAIRCLOUGH, N. Discurso e mudança social. Trad. MAGALHÃES, Izabel. Brasília : Editora Universidade de Brasília, 2001.

FÁVERO, L. L. et aliae. Oralidade e escrita; perspectivas para $o$ ensino de língua materna. São Paulo : Cortez, 1999.

HALLIDAY, M.A. K. Language as social semiotic. Londres : Edward Arnold, 1978.

HALLIDAY, M.A. K. e HASAN, R. Cohesion in English. Londres: Longman, 1976.

KRAMSCH, C. Interaction et discours dans la classe de langue. Paris: Hatier-Credif, 1984. 